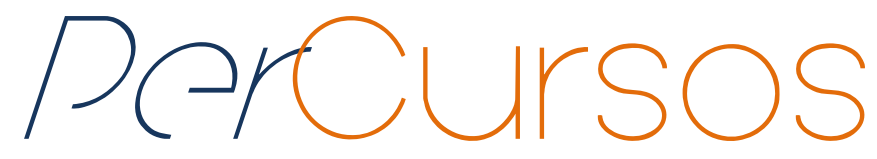

\title{
Digital images for libraries, archives and museums (DILAM): apresentação de um modelo conceitual ${ }^{1}$
}

\begin{abstract}
Resumo
A expressiva quantidade de recursos informacionais, entre eles os imagéticos digitais, está relacionada às novas formas de comunicação da sociedade. Diante disso, procedimentos necessários para localização e recuperação são tarefas complicadas para o profissional e para o próprio usuário pela variedade de recursos a serem descritos. Da mesma forma, instituições com uma proposta de convergência para determinados tipos de acervo crescem visando a interoperabilidade sintática de registros. Nesse contexto, é possível questionar como integrar os princípios descritivos para os contextos da Arquivologia, Biblioteconomia e Museologia do recurso imagético digital? Objetiva-se apresentar o modelo conceitual Digital Images for Libraries, Archives and Museums (DILAM) enfatizando as suas entidades e os atributos responsáveis pela integração aos contextos e ao recurso imagético digital. A pesquisa é classificada como teórico-aplicada e qualitativa, em relação aos objetivos de desenvolvimento, e exploratória pela realização de um levantamento bibliográfico de nível nacional e internacional. Os resultados apresentam as três etapas de criação do modelo, 1) definição de requisitos funcionais para os usuários, 2) definição dos metadados apropriados ao recurso imagético digital e 3) definição das entidades e criação do modelo DILAM. Conclui que a interlocução entre arquivos, bibliotecas e museus não reflete em uma unificação, mas expressa a colaboração e cooperação em relação aos avanços tecnológicos presentes na representação e organização da informação.
\end{abstract}

Palavras-chave: Imagens digitais; Arquivos; Bibliotecas; Museus.

\author{
Ana Carolina Simionato \\ Doutora em Ciência da \\ Informação pela Universidade \\ Estadual Paulista "Júlio de \\ Mesquita Filho" - UNESP. \\ Professora da Universidade \\ Federal de São Carlos - UFSCAR. \\ Brasil \\ acsimionato@ufscar.br
}

\section{Plácida Leopoldina Ventura Amorim da Costa Santos}

Doutora em Lingüística pela

Universidade de São Paulo - USP.

Professora da Universidade

Estadual Paulista "Júlio de

Mesquita Filho" - UNESP.

Brasil

placida@marilia.unesp.br

\section{Para citar este artigo:}

SIMIONATO, Ana Carolina; SANTOS, Plácida Leopoldina Ventura Amorim da Costa. Digital images for libraries, archives and museums (DILAM): apresentação de um modelo conceitual. Revista PerCursos, Florianópolis, v. 17, n.34, p. 68 - 90, maio/ago. 2016.

\section{DOI: 10.5965/1984724617342016068}

http://dx.doi.org/10.5965/1984724617342016068

\footnotetext{
${ }^{1}$ Texto apresentado no XVI ENANCIB, na modalidade Comunicação Oral.
} 


\title{
Digital images for libraries, archives and museums (DILAM): conceptual model a presentation
}

\begin{abstract}
A significant amount of information resources, including digital imagery, are related to new forms of communication in society. Therefore, procedures for location and retrieval are complicated tasks for the professional and the user himself by the variety of resources to be described. Similarly, institutions with a proposal of convergence for certain types of assets grow aiming syntactic interoperability records. In this context, the question is how integrate the descriptive principles for the contexts of Archival, Library and Museum studies of digital image feature? The objective is to present the Digital Images for Libraries, Archives and Museums (DILAM) conceptual model emphasizing their entities and attributes responsible for integrating the contexts and digital image resource. The research is classified as theoretical and applied and qualitative, in relation to the development goals, and exploration for carrying out a literature review of national and international levels. The results show the three steps of creating the model: 1) definition of functional requirements for users, 2) definition of metadata appropriate to digital imagery feature, and 3) the entities and creation of DILAM model. It concludes that the dialogue between archives, libraries and museums, not reflected in a unification, but expresses collaboration and cooperation in relation to technological advances present in the representation and organization of information.
\end{abstract}

Keywords: Digital images; Archives; Libraries; Museums. 


\section{Introdução}

A necessidade de tornar acessíveis e disponíveis as imagens digitais em repositórios, banco de imagens e catálogos insere-se aos procedimentos metodológicos da área de Ciência da Informação e ao conjunto dos aspectos tecnológicos envolvidos na representação da informação.

O conjunto de procedimentos metodológicos da Ciência da Informação ( $\mathrm{Cl}$ ) deriva do estudo, análise, disseminação, preservação e representação para o acesso aos registros informacionais. (BUCKLAND, 1991). O objeto documental também dito como recurso informacional, definido como "[...] a informação objetivada [...] em uma estrutura analógica e/ou digital, com valor informacional que caracteriza a sua concepção intelectual expressa na corporificação de manifestações estruturadas na forma de itens" (SANTOS; SIMIONATO; ARAKAKI, 2014, p. 148).

A representação desse recurso informacional deve corresponder à forma expressa de sua retratação, isso condiz com que a imagem seja adequadamente tratada nos conceitos da área de $\mathrm{Cl}$, sendo que ao mesmo tempo é considerado como desafio para área, representar e organizar atributos de recursos informacionais que elucidem as características principais considerando as ocasiões necessárias de acesso e localização feitas pelos usuários.

Glushko (2013) e Svenonius (2000) enfatizam a preocupação para as questões sobre o domínio de recursos informacionais, sendo os domínios conceitualmente definidos por campos de estudo mais abrangentes inseridos na tipologia de recursos informacionais, como imagéticos, bibliográficos, sonoro, entre outros. Da mesma forma, essa preocupação deve se atentar a representação dos recursos e suas propriedades amplas, ou seja, devem descrevê-los a fim de tornar o recurso único.

É possível também apontar outra preocupação, que corresponde à integração dos princípios descritivos dos contextos da Arquivologia, Biblioteconomia e Museologia, em razão desse tipo do recurso imagético pertencer aos acervos destas unidades de informação, incluindo as Galerias de Arte, pelo valor que a imagem possui como patrimônio artístico, cultural, preservação da memória, de comprovação, entre outros. 
Parte dessa preocupação também está inserida nos estudos e eventos sobre o movimento de integração destes contextos como destacados por alguns autores, entre Homulus (1990), Smit (1993), Smit e Barreto (2002), Guimarães (2008), Tanus e Araújo (2012) e Marcondes (2012).

Esse trabalho inicia em uma camada invisível e intangível ao usuário final, estruturando uma abordagem que proporcione possibilidades de convergência para que os dados desses diferentes contextos tenham interligações, favorecendo a recuperação e localização dos recursos pelo usuário.

Nesse caso, são consideradas as diferenças organizacionais e as necessidades da análise documental realizada em cada unidade informacional, a compreensão do conjunto da imagem e as convergências para o contexto arquivístico, biblioteconômico e museológico. Considera que o ambiente digital é um meio convergente de diversos usuários, independentemente do vínculo institucional formado, ou seja, o ambiente digital pode agrupar diferentes grupos informacionais.

Para isso, foi pressuposto que os princípios descritivos dos contextos arquivístico, biblioteconômico e museológico são fatores que subsidiam a construção de um modelo conceitual, que possa ser relacionado com os atributos de recursos imagéticos em ambientes digitais a partir do seu domínio. Sendo assim, o objetivo desse trabalho é apresentar o modelo conceitual Digital Images for Libraries, Archives and Museums (DILAM) enfatizando as suas entidades e os atributos responsáveis pela integração aos contextos e ao recurso imagético digital.

\section{Metodologia}

A pesquisa é classificada como natureza teórico-aplicada e qualitativa, objetivando gerar novas possibilidades para construção de registros informacionais na representação e organização de imagens digitais. Em relação aos objetivos do trabalho para integração dos contextos arquivístico, biblioteconômico e museológico, essa pesquisa é classificada como exploratória. Em relação aos procedimentos técnicos, recorre-se à pesquisa 
bibliográfica, com o levantamento realizado em nível nacional e internacional em fontes de pesquisa primárias, secundárias e terciárias.

Em relação ao levantamento bibliográfico, o período selecionado foi o de 2000 a 2014, levando em consideração que algumas obras deveriam ser citadas independente da data. As fontes utilizadas no levantamento bibliográfico foram: Biblioteca Digital Brasileira de Teses e Dissertações (BDTD), Base de Dados Referenciais de Artigos de Periódicos em Ciência da Informação (BRAPCI), P@rthenon UNESP, Portal de Periódicos da Capes, Google Acadêmico, Scientific Electronic Library Online (SciELO) e a Web of Science, tendo como resultados artigos, teses e dissertações, capítulos de livros e livros.

O método escolhido para o desenvolvimento do modelo foi a modelagem Entidade-Relacionamento, já trabalhada nos Requisitos Funcionais para Dados Imagéticos Digitais (RFDID) por Simionato (2012), sendo sua base espelhada na estrutura dos Functional Requirements for Bibliographic Records (FRBR).

\section{A imagem digital e os princípios descritivos na Arquivologia, Biblioteconomia e Museologia}

A partir das redes sociais e do ambiente digital, o recurso imagético teve uma ampla proporção de aceitação e utilização, o que facilitou ainda mais a sua criação. As características que o diferenciam da imagem analógica, são relativas à gênese digital. Estas propriedades são importantes e, principalmente, em alguns casos, podem ser recuperadas pelos dados Exchangeable Image File Format (EXIF) ou pelas diferentes extensões. As extensões podem ser nomeadas por imagens vetoriais, ou seja, imagens geradas a partir de descrições geométricas de formas e se diferenciam das imagens bitmap ou mapa de bits; ou raster, que são geradas a partir de pontos minúsculos diferenciados por suas cores.

Todavia, é importante lembrar que caso os recursos não estejam descritos adequadamente ao tipo de ambiente inserido, ocorrerão problemas em sua localização e, consequentemente, o usuário não recuperará o que deseja. Segundo Sánchez Vigil 
(2006), o documento imagético está disperso nos acervos apresentando variedades (fotografias, negativos, imagens digitais) e dependendo do tipo de instituição que as incorpora no acervo são diferenciadas pela sua aplicação e função. Após a aquisição, as imagens são distinguidas pelo seu assunto, tratadas de modo aleatório e pouco utilizados os vocabulários controlados e a indexação, e em raros casos pela autoria e título.

Para possibilitar a localização, acesso e recuperação das imagens, vários tratamentos informacionais e criações computacionais são necessárias, uma delas é a padronização dos atributos, realizada por instrumentos de descrição. A “[...] definição dos elementos, dos atributos de descrição para a representação é realizada em diferentes níveis nas unidades de informação em que atuam" (SANTOS, 2013, não paginado), em razão de que os elementos identificados devem se constituir de propriedades que identificam o tipo de recurso informacional.

No entanto, ao diferenciar o tipo de instituição como arquivos, bibliotecas e museus, também diverge o tratamento do tipo de recurso. As diferenças do tratamento informacional estão presentes desde os atributos derivados à lógica representacional de cada contexto até os atributos do próprio recurso informacional. Em razão das dissonâncias salientadas pelos aspectos organizacionais e representacionais, tendências internacionais estão preocupadas em sanar desafios entre as áreas, como a cooperação de coleções, registros e dados entre de arquivos, bibliotecas e museus. Como destaca Marcondes (2012, p. 188),

Alinhamentos semânticos facilitam a navegação através de dados abertos interligados entre recursos informacionais diferentes através dos links semânticos entre entidades em diferentes conjuntos de dados. $\mathrm{Na}$ área de arquivos, bibliotecas e museus, alguns esforços de alinhamento semântico já foram feitos, como entre os modelos FRBR (1998) (da área de bibliotecas) e o CIDOC CRM (da área de museus), resultando disso o FRBRoo.

O estudo da descrição de imagens na Arquivologia foi relacionado às correntes teóricas e metodológicas que definem as formas de representação no ciclo de vida dos 
documentos. Nas correntes mais tradicionais do campo, como a diplomática arquivística e a pós custodial, em que a descrição somente deverá ser realizada na fase permanente. Já na arquivística integrada, proposta por Rousseau e Couture (1998), a descrição inicia-se a partir da criação/produção do documento na instituição, preservando os atributos já definidos na sua fase corrente.

A arquivística integrada é uma forma gerada e conduzida ao propósito da organização; dentro destas funções, pode ser concentrada conforme as formalidades da descrição e da classificação (ROUSSEAU; COUTURE, 1998). Essa corrente garante a unicidade das intervenções nos documentos, aplicando o princípio das três idades e ainda se caracterizando pela construção lógica dos metadados descritivos para o arranjo e pela ordem original dos subgrupos, denominadas como séries, dos documentos.

De certa forma, a utilização da corrente da arquivística integrada garante o acesso aos documentos desde a fase inicial, e, ainda, poupa o retrabalho do profissional arquivista evitando novas descrições ao longo do processo documental. Ressalva-se que na arquivística integrada, os fundamentos apoiam o tratamento descritivo para o Gerenciamento Eletrônico de Documentos (GED) definidos por Rousseau e Couture (1998).

No entanto, os instrumentos arquivísticos mais utilizados como a International Standard Archival Description General - ISAD (G) não acompanharam o mesmo desenvolvimento organizacional e representacional junto às novas possibilidades do meio digital, assim não conseguem explorar todo o potencial e seus alinhamentos com o desenvolvimento de seus modelos conceituais, como o Conceptual Model for Archival Description (CMAD) e as iniciativas Modular Requirements for Records Systems (MoReq) e Modelo de Entidades e Relacionamentos do e-ARQ Brasil.

Já a Biblioteconomia, pelo seu próprio desfecho histórico apresenta uma maior dinâmica em relação aos instrumentos descritivos e aos modelos conceituais. Guinchat e Menou (1994, p. 101) afirmam que a catalogação deve “[...] fornecer uma representação do documento que é descrito de uma forma única e não ambígua, o que permite identificá-lo, localizá-lo, representá-lo nos catálogos correspondentes e recuperá-lo." 
A catalogação permite que o catálogo possa multidimensionar as escolhas, para que o usuário encontre o material desejado. Segundo Santos e Pereira (2014, p. 71),

O processo de Catalogação de um recursos, em suas diversas etapas, demanda tempo, custos, e conhecimento especializados para a análise de um dado bibliográfico e para utilização dos instrumentos de trabalho da representação, como, por exemplo, os códigos, as normas, os padrões de metadados, os formatos de intercâmbio de dados bibliográficos, os requisitos funcionais, as listas de cabeçalhos de assuntos, as listas de cabeçalho de autor, os manuais e outros catálogos, para garantir um padrão mínimo de qualidade e padronização.

Portanto, o processo de catalogação além de garantir a unicidade ao recurso informacional em uma forma sucinta e estruturada dos dados, apresenta certas características. As disposições da catalogação estão relacionadas às novas formas de representação como o Functional Requirements for Bibliographic Records (FRBR), por exemplo. Com a concepção do FRBR, o entendimento do processo de representação do recurso informacional foi revisto e, com isso, novos relacionamentos entre os recursos informacionais foram possíveis.

Essa percepção influenciou diretamente a estrutura de alguns códigos de catalogação como a International Standard Bibliographic Description (ISBD) em sua versão consolidada e o Anglo-American Cataloguing Rules, second edition revised (AACR2r) que se diferenciam por suas estruturas e tipos de recursos como livros e materiais cartográficos. Dessa forma, a ISBD que possuía diversas publicações, transformou tudo em apenas um único manual e o AACR2r que subdividia seus capítulos direcionados à descrição de um tipo de recurso está sendo substituída pelo Resource Description and Access (RDA).

Já a Museologia é reconhecida por sua instituição condizer com a coleção e com a responsabilidade de induzir a ampliação dos conhecimentos sobre a humanidade e suas técnicas, ou seja, toda forma representacional reluz as fontes informacionais daquela determinada imagem digital e de sua coleção. Assim, “[...] liga-se diretamente à morfologia do objeto, isto é, diz respeito a materiais e técnicas de confecção, a formas, 
ornamentos, a partes constituintes, a funções utilitárias para as quais foi concebido e a significados simbólicos relacionados às formas materiais de representação" (BARBUY, 2002, p. 71).

O catálogo na Museologia "[...] trata-se de um meio de comunicação típico e objetivo para difusão de suas propostas. Através dele o museu comunica os estudos e pesquisas que vêm sendo realizados sobre um determinado aspecto, utilizando seus próprios meios de interpretação [...]” (CAMARGO-MORO, 1986, p. 225).

Os instrumentos de representação na Museologia específicos são pouco abordados pela diversidade de campos que são necessários para os registros. Mesmo que nem todos sejam preenchidos, os campos necessários são: o tipo do material, técnica utilizada, procedência, história de exposição, as considerações de instalação e valor de avaliação.

\section{O modelo conceitual DILAM}

Ao contrário do escopo de criar um novo padrão de metadados para a imagem digital, o modelo DILAM tem como objetivo equivaler os princípios descritivos dos contextos da Arquivologia, Biblioteconomia e Museologia, de tal forma que não trate de forma diminutiva, mas sim de forma colaborativa e seja complementar ao planejamento de dados estruturados em um modelo conceitual.

Assim, o modelo DILAM foi desenvolvido a partir dos estudos denominados como modelagem DILAM (SIMIONATO, 2015), elaborada a partir de três etapas, que constituem: 1) definição de requisitos funcionais para os usuários; 2) definição dos metadados apropriados ao recurso imagético digital e; 3 ) definição das entidades e criação do modelo DILAM.

A definição dos requisitos funcionais foi baseada no aprofundamento dos estudos sobre o recurso imagético digital, como também sobre cada uma das necessidades de cada contexto e seus usuários. 
Os requisitos funcionais na Ciência da Informação também são encontrados com a terminologia user tasks ou tarefas do usuário. Essas tarefas coincidem com as propriedades que cada particularidade da modelagem deve priorizar. Outro ponto considerado foi a harmonização entre os modelos conceituais já finalizados na área de Ciência da Informação, como o FRBR e os Requisitos Funcionais para Recursos Imagéticos Digitais (RFDID), proposto por Simionato (2012).

Dessa forma, os requisitos conceituais previstos na modelagem e caracterizados no modelo DILAM, foram planejados a partir dos modelos conceituais e propostas da Arquivologia, Biblioteconomia e Museologia, que incluem Functional Requirements for Bibliographic Records (FRBR), Autoridade (FRAD) e Assunto (FRSAD), o domínio da arquivística, Conceptual Model for Archival Description (CMAD) e o Modular Requirements for Records Systems (MoReq) e o domínio museológico, Conceptual Reference Model (CRM).

Assim, os requisitos funcionais para o DILAM são:

- Encontrar materiais que correspondam aos critérios estabelecidos de pesquisa do usuário;

- Identificar uma entidade;

- Selecionar uma entidade que é adequada para as necessidades do usuário;

- Explorar os recursos imagéticos de uma coleção, utilizando atributos e relações entre os recursos, usando atributos e relacionamentos;

- Escolher os assuntos para que possam encontrar as imagens desejadas, usando atributos e relacionamentos;

- Reconhecer as responsabilidades de criação de um recurso imagético digital, e buscar as autorias, usando atributos e relacionamentos; e

- Obter o recurso imagético, selecionado e identificado.

O segundo passo foi a escolha dos metadados apropriados, derivados do método crosswalk (ST. PIERRE; LAPLANT, 1998). Os crosswalks são usados para "[...] comparar elementos de metadados de um esquema ou elemento definido para um ou mais outros 
esquemas [...]” (BACA, 2008, p. 47, tradução nossa) e também da metodologia BEAM proposto por Santos, Simionato e Arakaki (2014).

Os padrões de metadados utilizados no crosswalk foram: Anglo-American Cataloguing Rules, second edition revised (AACR2r), Cataloging Cultural Objects (CCO), Categories for the Description of Works of Art (CDWA), Categories for the Description of Works of Art Lite (CDWA Lite), Describing Archives: a content standard (DACS), Dublin Core (DC), Encoded Archival Description (EAD), Graphic Materials, International Standard Archival Description General (ISAD(G)), International Standard Bibliographic Description, consolidated edition (ISBD), Resource Description and Access (RDA), Rules for Archival Description (RAD) e SPECTRUM.

Os resultados dos crosswalks foram base para o desenvolvimento do último passo, a criação das entidades para o modelo DILAM. Inicialmente, foi determinado que as entidades da modelagem entidade-relacionamento, no escopo da desvinculação de um registro monolítico sem relacionamentos, como na estrutura MARC 21, para um registro construído a partir de integrações da imagem digital, principalmente, entre áreas.

O modelo conceitual DILAM é visualizado pela figura 1. 


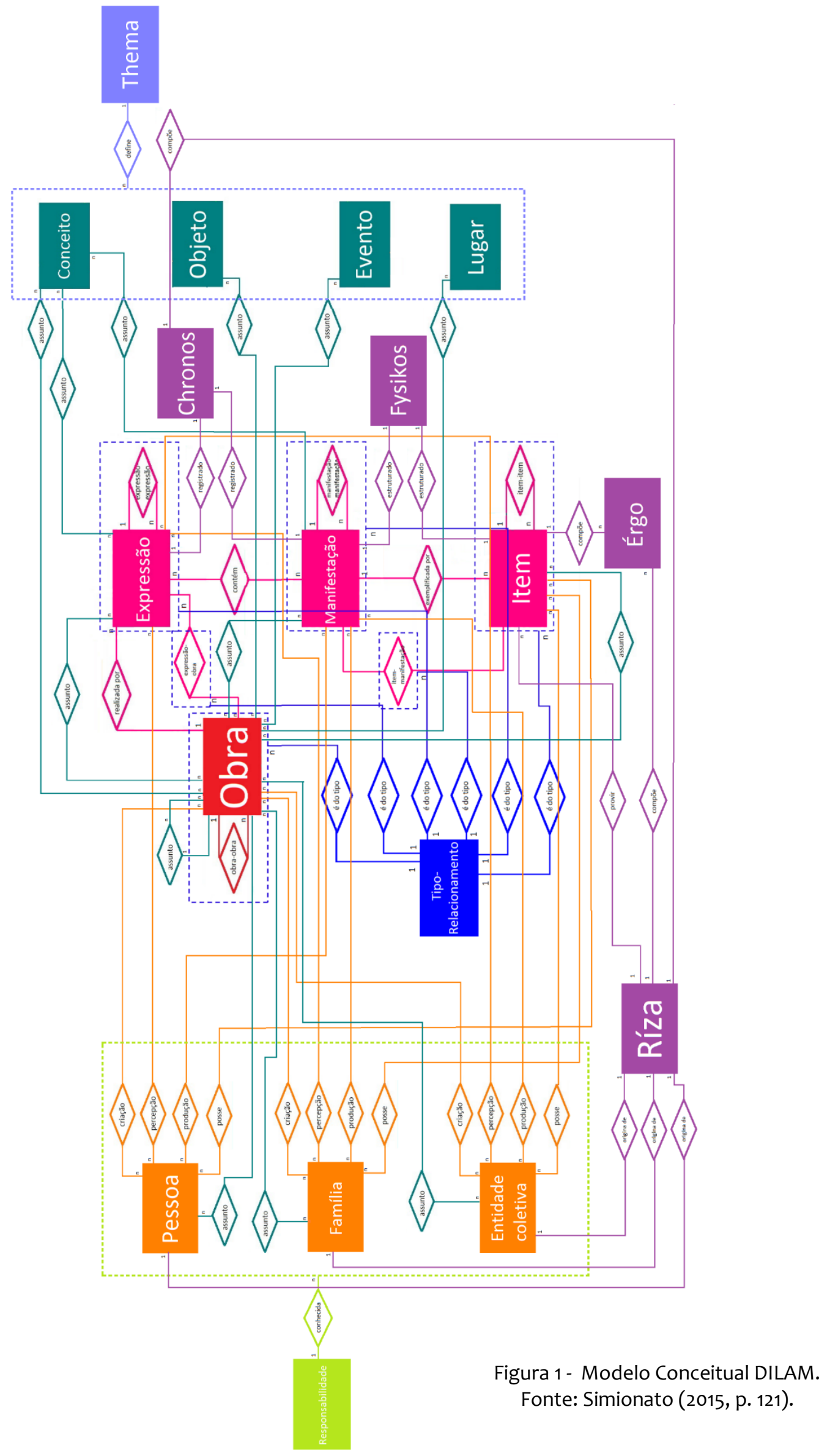


Como visto na figura 1, as entidades são compatíveis com as entidades já compostas da família FRBR e, por isso, foram mantidas, Obra, Expressão, Manifestação, Item (Grupo 1), Pessoa, Família, Entidade Coletiva (Grupo 2), Conceito, Objeto, Evento e Lugar (Grupo 3).

Outras entidades foram criadas para acrescentar e subsidiar alguns relacionamentos entre as entidades. Tipo-Relacionamento, que descreve a que tipo de relacionamento pertence o relacionamento complementar entre as entidades do Grupo 1 e Obra; Responsabilidade, entidade que relaciona ao controle de autoridade do Grupo 2 e Obra; e Thema, entidade que relaciona ao controle de assunto do Grupo 3 e Obra.

Para a integração entre os contextos arquivístico, biblioteconômico e museológico, a modelagem conceitual precisou que algumas entidades fossem incorporadas ao seu escopo. Desse modo, trariam os requisitos específicos de cada contexto. Entre os modelos de Museologia e Arquivologia, algumas características se mostram importantes e comuns em relação à descrição: tempo, propriedades físicas, origem do recurso informacional (procedência e proveniência) e os processos técnicos dos recursos imagéticos, como a classificação de documentos. Outro destaque foi aos 'fundos', 'séries', 'arquivos' do documento, mas é compreendido que nesse modelo conceitual inserem-se as abstrações de uma obra, expressão e manifestação por serem propriedades de organização do recurso. Por isso, foram criadas quatro novas entidades que relacionam entre as outras já mencionadas. As entidades são: Chronos (tempo), Fysikos (propriedades físicas), Rízo (origem o recurso) e Érgo (atividades técnicas) (SIMIONATO, 2015).

Para tanto, um melhor entendimento sobre as entidades do modelo DILAM será feito a partir do quadro 1, que descreve cada uma das entidades e seus relacionamentos. 


\begin{tabular}{|c|c|}
\hline $\begin{array}{c}\text { ENTIDADES DO MODELO } \\
\text { DILAM }\end{array}$ & DESCRIÇÃO \\
\hline Obra & $\begin{array}{l}\text { É a abstração da concepção intelectual do autor, ou seja, é } \\
\text { uma entidade definida como a que o autor pensou antes de } \\
\text { se tornar concreta. Nesta entidade, a concepção de um } \\
\text { recurso imagético não está ligada a uma concepção } \\
\text { primária; inicialmente, o autor não compõe a obra em um } \\
\text { suporte, mas somente, a conceitua. }\end{array}$ \\
\hline Expressão & $\begin{array}{l}\text { Condiz com a realização intelectual ou artística, ou seja, } \\
\text { podemos dizer que é a elaboração da obra, é quando o } \\
\text { autor, depois de já feita a concepção de uma, obra decide } \\
\text { traduzi-la na forma imagética e se preocupa em como será a } \\
\text { imagem. Possui o relacionamento de 'estar em', 'incorporar' } \\
\text { e 'conter' com a manifestação. }\end{array}$ \\
\hline Manifestação & $\begin{array}{l}\text { A Manifestação atribui a forma física e concreta da } \\
\text { expressão de uma obra. Pode ser uma imagem analógica, } \\
\text { digital ou as duas ao mesmo tempo; será o suporte de } \\
\text { registro da imagem. Possui o relacionamento de } \\
\text { 'exemplificar' com o item. }\end{array}$ \\
\hline Item & $\begin{array}{l}\text { A imagem que o usuário encontrará em um catálogo, banco } \\
\text { ou repositório de imagens. }\end{array}$ \\
\hline Tipo-Relacionamento & $\begin{array}{l}\text { Descreve a que tipo de relacionamento pertence } 0 \\
\text { relacionamento complementar as entidades do Grupo } 1 \text { e } \\
\text { Obra, Responsabilidade, entidade que relaciona ao controle } \\
\text { de autoridade do Grupo } 2 \text { e Obra. Os relacionamentos } \\
\text { podem ser de adaptação, complemento, imitação, sucessão, } \\
\text { suplemento, sumarização, transformação e todo para a } \\
\text { parte. }\end{array}$ \\
\hline Pessoa & $\begin{array}{l}\text { É a abstração de um indivíduo, o principal responsável pela } \\
\text { criação, ou ainda a responsabilidade da realização de uma } \\
\text { obra. Ou seja, o responsável pela captura da imagem digital } \\
\text { ou por sua realização. No caso, não é importante que o } \\
\text { fotógrafo seja amador ou profissional, ou se o responsável } \\
\text { pela criação foi um telescópio. }\end{array}$ \\
\hline Família & $\begin{array}{l}\text { À Família é atrelada não a responsabilidade de criação, mas a } \\
\text { detentora dos direitos autorais do indivíduo criador. E seus } \\
\text { componentes familiares estarão ligados à pessoa. Como da } \\
\text { mesma forma é a Entidade coletiva, contudo, o que difere } \\
\text { são as formas de parentesco dos responsáveis. }\end{array}$ \\
\hline Entidade coletiva & $\begin{array}{l}\text { São as organizações ou grupos de indivíduos responsáveis } \\
\text { pelo conteúdo intelectual da imagem digital, inclusive } \\
\text { grupos temporários (encontros, conferências, reuniões, } \\
\text { festivais, etc.) e autoridades territoriais como uma }\end{array}$ \\
\hline
\end{tabular}




\begin{tabular}{|c|c|}
\hline & federação, um estado, uma região, entre outros. \\
\hline Responsabilidade & $\begin{array}{l}\text { Auxilia na identificação das principais formas de autoridade } \\
\text { para o usuário. Sua atribuição deriva-se das necessidades } \\
\text { encontradas no modelo conceitual FRAD. Logo, atribui seu } \\
\text { relacionamento a uma entidade ser conhecida por uma } \\
\text { responsabilidade. }\end{array}$ \\
\hline Conceito & $\begin{array}{l}\text { Representa uma noção abstrata ou uma ideia que pode ser } \\
\text { ampla ou específica, abrangendo abstrações de uma obra. } \\
\text { Essas abstrações podem ser termos que identifiquem as } \\
\text { áreas de conhecimento, disciplinas, escolas de pensamento, } \\
\text { teorias; ou ainda as técnicas fotográficas que podem ser } \\
\text { incorporadas às imagens desde a sua concepção. }\end{array}$ \\
\hline Objeto & $\begin{array}{l}\text { Está relacionado a uma coisa material, que abrange uma } \\
\text { completa categoria de coisas materiais que podem incluir o } \\
\text { conteúdo de uma obra: objetos da natureza, objetos da } \\
\text { criação humana ou objetos que já não existam. }\end{array}$ \\
\hline Evento & $\begin{array}{l}\text { Entidade que inclui as ações, ocorrências ou acontecimentos } \\
\text { que derivaram ou ao que a imagem se encontra, como um } \\
\text { momento histórico, época, período de tempo. }\end{array}$ \\
\hline Lugar & $\begin{array}{l}\text { É a localização ou uma série de localizações como: terrestres } \\
\text { e extraterrestres, históricas ou contemporâneas, } \\
\text { características geográficas e jurisdições geopolíticas. }\end{array}$ \\
\hline Thema & $\begin{array}{l}\text { É uma entidade para que os relacionamentos de todos os } \\
\text { assuntos se atrelem a apenas um, incorporando as } \\
\text { entidades de Conceito, Objeto, Evento e Lugar. }\end{array}$ \\
\hline Chronos & $\begin{array}{l}\text { Foi identificada nos contextos e na definição dos atributos, a } \\
\text { necessidade de arquivos e museus em destacarem o tempo } \\
\text { de uma obra. Principalmente para Arquivologia, a entidade } \\
\text { determina em questão a temporalidade do recurso } \\
\text { imagético e em qual forma será armazenada. Possui } \\
\text { relacionamentos de registro. }\end{array}$ \\
\hline Fysikos & $\begin{array}{l}\text { A necessidade de uma entidade para propriedades físicas } \\
\text { parte do escopo da Museologia na criteriosa avaliação do } \\
\text { estado em que os recursos se encontram; no caso, a imagem } \\
\text { analógica se houve alguma danificação ou outra ocorrência. } \\
\text { Possui relacionamentos de estrutura. }\end{array}$ \\
\hline Rízo & $\begin{array}{l}\text { Abrange as necessidades específicas para a identificação da } \\
\text { procedência e proveniência. Possui relacionamentos de } \\
\text { origem. }\end{array}$ \\
\hline Érgo & $\begin{array}{l}\text { Corresponde às atividades que necessitam ser relatadas, } \\
\text { como a classificação, avaliação e curadoria. Possui } \\
\text { relacionamentos de composição. }\end{array}$ \\
\hline
\end{tabular}


Algumas entidades, principalmente as correspondentes ao Grupo 3, possibilitam que a descrição seja utilizada a partir dos EXIF como fonte de informação. No entanto, para que sejam evitadas anomalias de alguns atributos, o quadro 2 apresenta cada entidade, os relacionamentos e seus respectivos atributos, que serão utilizados para a descrição das entidades de forma integral, já previsto pela etapa anterior no crosswalk realizado.

\begin{tabular}{|c|c|}
\hline ENTIDADE & ATRIBUTO \\
\hline Obra & $\begin{array}{c}\text { Data de criação* } \\
\text { Data relacionada ao título } \\
\text { Nome(s) do(s) produtor(es)* } \\
\text { Nota descritiva* } \\
\text { Título * } \\
\text { Título do criador }\end{array}$ \\
\hline Obra-obra & $\begin{array}{l}\text { Tipo de relacionamento* } \\
\text { Descrição da derivação* } \\
\text { Extensão do autor } \\
\text { Qualificação do autor } \\
\text { Título do autor* } \\
\text { Data* } \\
\text { Data de criação* } \\
\text { Data relacionada ao título } \\
\text { Localização da criação* } \\
\text { Notas* }\end{array}$ \\
\hline Expressão & $\begin{array}{c}\text { Data de criação* } \\
\text { Data de relação à obra* } \\
\text { Data relacionada ao título } \\
\text { Data* } \\
\text { Descrição da derivação } \\
\text { Descrição da edição* } \\
\text { Nome(s) do(s) produtor(es)* } \\
\text { Nota descritiva* } \\
\text { Número da edição } \\
\text { Número de identificação* } \\
\text { Tipo de relação à obra } \\
\text { Título equivalente* } \\
\text { Título da expressão* } \\
\text { Título do criador* } \\
\text { Notas* }\end{array}$ \\
\hline Expressão-expressão & $\begin{array}{l}\text { Descrição da derivação } \\
\text { Descrição da edição* }\end{array}$ \\
\hline
\end{tabular}




\begin{tabular}{|c|c|}
\hline & $\begin{array}{l}\text { Idioma* } \\
\text { Notas* }\end{array}$ \\
\hline Expressão-obra & $\begin{array}{c}\text { Data* } \\
\text { Data de criação* } \\
\text { Data relacionada ao título* } \\
\text { Idioma* } \\
\text { Notas* }\end{array}$ \\
\hline Manifestação & $\begin{array}{c}\text { Data de criação* } \\
\text { Data relacionada ao título } \\
\text { Nome(s) do(s) produtor(es)* } \\
\text { Nota descritiva* } \\
\text { Título da manifestação* } \\
\text { Designação de edição/impressão } \\
\text { Local de publicação/distribuição } \\
\text { Publicador/distribuidor } \\
\text { Data de publicação/distribuição } \\
\text { Fabricante } \\
\text { Indicação de série } \\
\text { Forma do suporte } \\
\text { Extensão do suporte } \\
\text { Meio físico } \\
\text { Modo de captura } \\
\text { Dimensões do suporte } \\
\text { Identificador da Manifestação } \\
\text { Fonte para aquisição/autorização de acesso } \\
\text { Notas* }\end{array}$ \\
\hline $\begin{array}{l}\text { Manifestação- } \\
\text { manifestação }\end{array}$ & $\begin{array}{l}\text { Data de criação* } \\
\text { Data relacionada ao título } \\
\text { Notas* }\end{array}$ \\
\hline Item & $\begin{array}{l}\text { Identificador do item* } \\
\text { Impressão digital } \\
\text { Restrições de acesso ao item* } \\
\text { Localização do item* } \\
\text { Notas* }\end{array}$ \\
\hline Item-manifestação & $\begin{array}{l}\text { Data de criação* } \\
\text { Localização* } \\
\text { Notas* }\end{array}$ \\
\hline Item-item & $\begin{array}{l}\text { Data de criação* } \\
\text { Localização* } \\
\text { Notas* }\end{array}$ \\
\hline Pessoa & $\begin{array}{c}\text { Nome da Pessoa* } \\
\text { Datas da Pessoa } \\
\text { Título da Pessoa } \\
\text { Outra designação associada à Pessoa } \\
\text { Notas* }\end{array}$ \\
\hline
\end{tabular}




\begin{tabular}{|c|c|}
\hline Família & $\begin{array}{c}\text { Nome da Família* } \\
\text { Datas da Família } \\
\text { Título da Família } \\
\text { Outra designação associada à Família } \\
\text { Notas* }\end{array}$ \\
\hline Entidade coletiva & $\begin{array}{c}\text { Nome da Entidade Coletiva* } \\
\text { Número associado à Entidade Coletiva } \\
\text { Local associado à Entidade Coletiva } \\
\text { Data associada à Entidade Coletiva } \\
\text { Outra designação associada à Entidade Coletiva } \\
\text { Notas* }\end{array}$ \\
\hline Responsabilidade & $\begin{array}{c}\text { Data de Falecimento* } \\
\text { Data de Nascimento* } \\
\text { Nacionalidade* } \\
\text { Nome da fonte das informações inseridas } \\
\text { Nome da Pessoa, Família ou Entidade Coletiva* } \\
\text { Nota biográfica da pessoa } \\
\text { Pessoas vinculadas à Pessoa, Família ou Entidade Coletiva } \\
\text { Profissão da pessoa* } \\
\text { Sexo* } \\
\text { Notas* }\end{array}$ \\
\hline Conceito & $\begin{array}{l}\text { Assunto principal de conceito* } \\
\text { Data atribuída ao assunto* } \\
\text { Notas* }\end{array}$ \\
\hline Objeto & $\begin{array}{l}\text { Assunto principal de objeto* } \\
\text { Notas* }\end{array}$ \\
\hline Evento & $\begin{array}{l}\text { Assunto principal de evento* } \\
\text { Data do evento* } \\
\text { Estilo do período histórico } \\
\text { Notas* }\end{array}$ \\
\hline Lugar & $\begin{array}{l}\text { Assunto principal de lugar* } \\
\text { Contexto arqueológico } \\
\text { Contexto arquitetônico } \\
\text { Locais relacionados } \\
\text { Local do evento* } \\
\text { Localização histórica } \\
\text { Tipo de evento - cultural } \\
\text { Tipo de evento - histórico } \\
\text { Tipo do período histórico* } \\
\text { Notas* }\end{array}$ \\
\hline Thema & $\begin{array}{l}\text { Descrição do conteúdo - atividade } \\
\text { Descrição do conteúdo - objeto } \\
\text { Escopo e conteúdo* } \\
\text { Nota descritiva do assunto* } \\
\text { Notas* }\end{array}$ \\
\hline
\end{tabular}




\begin{tabular}{|c|c|}
\hline & $\begin{array}{c}\text { Termos de indexação* } \\
\text { Termos genéricos* } \\
\text { Termos técnicos de iconografia } \\
\text { Notas* }\end{array}$ \\
\hline Chronos & $\begin{array}{c}\text { Descrição sobre a temporalidade* } \\
\text { Datas associadas a manifestação } \\
\text { Datas associadas a expressão } \\
\text { Notas* }\end{array}$ \\
\hline Fysikos & $\begin{array}{c}\text { Abertura da lente } \\
\text { Coloração* } \\
\text { Compensação de exposição } \\
\text { Contraste* } \\
\text { Descrição das dimensões* } \\
\text { Distância focal } \\
\text { Extensão* } \\
\text { Flash* } \\
\text { Forma* } \\
\text { Formato / Tamanho* } \\
\text { ISO* } \\
\text { Marcas d'água* } \\
\text { Materiais / Técnicas de Descrição* } \\
\text { Materiais / Técnicas de Extensão* } \\
\text { Nitidez* } \\
\text { Orientação* } \\
\text { Saturação* } \\
\text { Tamanho } \\
\text { Tipo de extensão* } \\
\text { Tipo de dimensões } \\
\text { Unidade das dimensões } \\
\text { Valor das dimensões* } \\
\text { Condição do Item } \\
\text { Histórico de tratamento } \\
\text { Plano de tratamento } \\
\text { Notas* }\end{array}$ \\
\hline Rízo & $\begin{array}{c}\text { Descrição da procedência* } \\
\text { Descrição da proveniência } \\
\text { Estatuto Jurídico relacionado } \\
\text { História administrativa/Biografia do Criador/Produtor* } \\
\text { História da custódia* } \\
\text { Procedência* } \\
\text { Proveniência do Item } \\
\text { Marcas/inscrições } \\
\text { Histórico de exibição } \\
\text { Notas* }\end{array}$ \\
\hline Érgo & Descrição do proprietário / agente* \\
\hline
\end{tabular}

Notas*

Datas associadas a manifestação

Datas associadas a expressão

ertura da lente

nsação de exposição

ão das dimensões*

istância focal

Extensão*

Flash*

/ Tamanho*

Marcas d'água*

Materiais / Técnicas de Descrição*

Nitidez*

Orientação*

Saturação*

nidade das dimensões

alor das dimensões*

作 


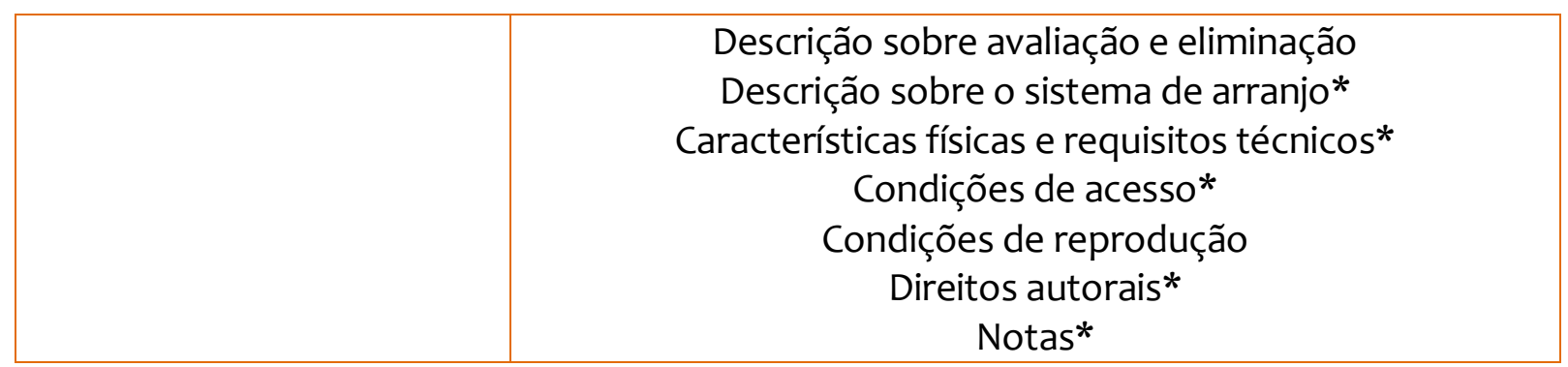

Quadro 2 - Atribuição de metadados para cada entidade e relacionamento da modelagem DILAM Fonte: Simionato, 2015, p. 133-136.

Os atributos com o asterisco (*) foram julgados como metadados obrigatórios e que são importantes para a identificação da entidade.

O processo de correspondência estará vinculado a padrões de metadados que subsidiam uma estrutura, ou seja, o formato para construção do registro. Por isso, em alguns momentos do crosswalk para os padrões de metadados específicos da Arquivologia, Biblioteconomia, Museologia e também para os recursos imagéticos digitais, um metadado corresponderá a muitos outros metadados do outro padrão; em diferentes casos, poderá ocorrer que diversos metadados serão direcionados a apenas outro do padrão de destino ou então, um metadado não corresponderá a nenhum outro e assim, o metadado não será utilizado.

\section{Considerações finais}

Considera-se que, em virtude das novas necessidades de vinculação e integração de dados, essa pesquisa traz uma abordagem para o contexto que já vivenciamos e conhecemos, a descrição em arquivos, bibliotecas e museus.

Nesse sentido, o modelo DILAM é uma proposta que acrescenta mais entidades já vistas no Requisitos Funcionais para Recursos Imagéticos Digitais (RFDID), apreciando as necessidades fundamentais dos contextos já explicitados, principalmente quando uma das questões fundamentais é a produção do item informacional.

Referente ao item informacional, ressalta-se a discrepância e as precauções para cada contexto. Em bibliotecas, o item pode ter várias cópias que possuem o mesmo processo documental - os exemplares, ao contrário do que acontece em arquivos e 
museus. Os cuidados com o recurso imagético para a Arquivologia e a Museologia são no sentido de que os documentos são tratados como únicos e não há exemplares, apenas cópias ou réplicas. Além disso, nesses dois casos há uma importância maior: o vínculo com o criador ou produtor, o qual é decisivo para incorporação na coleção.

A construção do modelo DILAM foi baseada nos principais modelos conceituais já consolidados e por isso, as principais entidades não teriam grandes ajustes em relação à persistência e consistência de dados. Isso quer dizer, que seja para um banco de dados, uma base de um catálogo cooperativo, é possível que contenha diversos tipos de abstrações com a mesma base conceitual. Isso pode ainda mais criar a interoperabilidade sintática de diversos tipos de recursos informacionais, bibliográficos, imagéticos, fílmicos, entre outros, em uma mesma base e catálogo.

Indica que o sentido desta interlocução entre as instituições não converge à unificação, pois cada contexto mostra diferenças. Mas é importante expressar e destacar por meio do modelo DILAM como isso pode ser colaborativo e cooperativo em relação aos avanços tecnológicos presentes na representação e organização da informação.

\section{Referências}

BACA, Murtha. (Ed.) Introduction to metadata. Los Angeles: Getty Publications, 2008.

BARBUY, Heloisa Maria Silveira. Os museus e seus acervos: sistemas de documentação em desenvolvimento. In: INTEGRAR: CONGRESSO INTERNACIONAL DE ARQUIVOS, BIBLIOTECAS, CENTROS DE DOCUMENTAÇÃO E MUSEUS, 1., São Paulo. Anais... São Paulo: Imprensa Oficial do Estado, 2002. p. 67-78.

BUCKLAND, Michael K. Information as thing?. Journal of the American Society of Science Information, v. 42, n. 5, p. 351-360. 1991. Disponível em:

<http://skat.ihmc.us/rid=1KR7VC4CQ-SLX5RG-5T39/BUCKLAND(1991)-

informationasthing.pdf >. Acesso em: 10 ago. 2015.

CAMARGO-MORO, Fernanda. Museu: aquisição e documentação. Rio de Janeiro: Livraria Eça, 1986. 
GLUSHKO, Robert. J. (Ed.) The discipline of organizing. Massachusetts; Londres: MIT Press, 2013.

GUIMARÃES, José. A. C. Ciência da informação, arquivologia e biblioteconomia: em busca do necessário diálogo entre o universo teórico e os fazeres profissionais. In: FUJITA, M. S. L.; GUIMARÃES, José. A. C. (Org.). Ensino e pesquisa em biblioteconomia no Brasil: a emergência de um novo olhar. São Paulo: Cultura Acadêmica, 2008.

GUINCHAT, Claire.; MENOU, Michel. Introdução geral as ciências e técnicas da informação e documentação. Brasília: IBICT, 1994.

HOMULUS, Peter. Museums to libraries: a family as collecting institutions. Art Library Journal, v. 15, n. 1, p. 11-13, 1990.

MARCONDES, Carlos. H. Linked Data: dados interligados e interoperabilidade entre arquivos, bibliotecas e museus na Web. Encontros Bibli, v. 17, n. 34, p. 171-192, 2012. Disponível em: <http://www.redalyc.org/articulo.oa?id=14723061012>. Acesso em: 10 ago. 2015.

ROUSSEAU, Jean-Yves.; COUTURE, Carol. Os fundamentos da disciplina arquivística. Lisboa: Dom Quixote, 1998.

SÁNCHEZ VIGIL, Juan Miguel. El documento fotográfico: historia, usos, aplicaciones. Madri: Ediciones Trea, 2006.

SANTOS, Plácida L. V. Amorim da Costa. Catalogação, formas de representação e construções mentais. Tendências da Pesquisa Brasileira em Ciência da Informação, v. 6, n. 1, 2013. Disponível em: <http://inseer.ibict.br/ancib/index.php/tpbci/article/viewArticle/100>. Acesso em: 10 ago. 2015.

SANTOS, Plácida L. V. Amorim da Costa; PEREIRA, Ana Maria. Catalogação: breve história e contemporaneidade. Niterói: Intertexto, 2014.

SANTOS, Plácida L. V. Amorim da Costa; SIMIONATO, Ana Carolina; ARAKAKI, Felipe Augusto. Definição de metadados para recursos informacionais: apresentação da metodologia BEAM. Informação \& Informação, v. 19, n. 1, 2014. p. 146-163. Disponível em: <http://www.uel.br/revistas/uel/index.php/informacao/article/view/15251>. Acesso em: 10 ago. 2015 .

SIMIONATO, Ana Carolina. Representação, acesso, uso e reuso da imagem digital. $141 \mathrm{f}$. 2012. Dissertação (Mestrado em Ciência da Informação) - Universidade Estadual Paulista "Júlio de Mesquita Filho", Faculdade de Filosofia e Ciências, Marília, 2012. Disponível em: <http://www.marilia.unesp.br/Home/Pos- 
Graduacao/Cienciadalnformacao/Dissertacoes/Simionato\%20A.C._mestrado_C.I._2012.pdf>. Acesso em: 10 ago. 2015.

SIMIONATO, Ana Carolina. Modelagem conceitual DILAM: princípios descritivos de arquivos, bibliotecas e museus para o recurso imagético digital. 2015. 200 f. Tese (Doutorado em Ciência da Informação) - Universidade Estadual Paulista 'Júlio de Mesquita Filho', Marília/SP, 2015. Disponível em: < http://www.marilia.unesp.br/Home/PosGraduacao/Cienciadalnformacao/Dissertacoes/simionato_ac_do_mar.pdf >. Acesso em: 10 ago. 2015.

SMIT, Johanna W. O documento audiovisual ou a proximidade entre as três Marias. Revista Brasileira de Biblioteconomia e Documentação, v. 26, n. 1, p. 81-85, 1993.

SMIT, Johanna W.; BARRETO, Aldo A. Ciência da Informação: base conceitual para a formação do profissional. In: VALENTIM, Marta P. (Org.) Formação do profissional da informação. São Paulo: Polis, 2002. p. 9-23.

ST. PIERRE, Margaret; LAPLANT, William P. Issues in crosswalking content metadata standards. Baltimore: NISO, 1998. Disponível em:

<http://www.niso.org/publications/white_papers/crosswalk>. Acesso em: 10 ago. 2015.

SVENONIUS, Elaine. The intellectual foundation of information organization.

Massachusetts: MIT Press, 2000.

TANUS, Gabrielle Francinne S. C.; ARAÚJO, Carlos Alberto de Ávila. Proximidades conceituais entre Arquivologia, Biblioteconomia, Museologia e Ciência da Informação.

Biblionline, v. 8, n. 2, 2012. Disponível em:

<http://www.ies.ufpb.br/ojs/index.php/biblio/article/view/14291>. Acesso em: 10 ago. 2015.

Recebido em: 19/09/2016 Aprovado em: 20/09/2016

Universidade do Estado de Santa Catarina - UDESC

Centro de Ciências Humanas e da Educação - FAED

Revista PerCursos

Volume 17 - Número 34 - Ano 2016 revistapercursos@gmail.com 